\title{
Potentiometric Titration of Polyhexamethylene Biguanide Hydrochloride with Potassium Poly(vinyl sulfate) Solution Using a Cationic Surfactant-selective Electrode
}

\author{
Takashi Masadome, ${ }^{* \dagger}$ Yuichi Yamagishi,* Masaki TaKano,* and Toshiaki HatTori** \\ *Department of Applied Chemistry, Faculty of Engineering, Shibaura Institute of Technology, \\ Toyosu, Koto, Tokyo 135-8548, Japan \\ **Department of Materials Science, Toyohashi University of Technology, Toyohashi 441-8580, Japan
}

\begin{abstract}
A potentiometric titration method using a cationic surfactant as an indicator cation and a plasticized poly(vinyl chloride) membrane electrode sensitive to the cationic surfactant is proposed for the determination of polyhexamethylene biguanide hydrochloride (PHMB-HCl), which is a cationic polyelectrolyte. A sample solution of PHMB-HCl containing an indicator cation (hexadecyltrimethylammonium ion, HTA) was titrated with a standard solution of an anionic polyelectrolyte, potassium poly(vinyl sulfate) (PVSK). The end-point was detected as a sharp potential change due to an abrupt decrease in the concentration of the indicator cation, HTA, which is caused by its association with PVSK. The effects of the concentrations of HTA ion and coexisting electrolytes in the sample solution on the degree of the potential change at the end-point were examined. A linear relationship between the concentration of PHMB-HCl and the end-point volume of the titrant exists in the concentration range from $2.0 \times 10^{-5}$ to $4.0 \times 10^{-4} \mathrm{M}$ in the case that the concentration of HTA is $1.0 \times 10^{-5} \mathrm{M}$, and that from $1.0 \times 10^{-6}$ to $1.2 \times 10^{-5} \mathrm{M}$ in the case that the concentration of HTA is $5.0 \times 10^{-6} \mathrm{M}$, respectively. The proposed method was applied to the determination of $\mathrm{PHMB}-\mathrm{HCl}$ in some contact-lens detergents.
\end{abstract}

(Received October 15, 2007; Accepted December 28, 2007; Published March 10, 2008)

\section{Introduction}

Recently, polyhexamethylene biguanide hydrochloride (PHMB$\mathrm{HCl}$ ), a cationic polyelectrolyte, is widely used for disinfectants in personal-care products for cosmetics and toiletries, and for sanitizers in swimming pools. So far, many determination methods for polyelectrolytes, such as a poly(diallyldimethylammonium chloride) (Cat-floc), were developed by using conductometry, ${ }^{1}$ turbidimetry, ${ }^{2}$ potentiometry using ion-selective electrodes (ISEs), ${ }^{3-21}$ colorimetric Toluidine Blue (TB) method, ${ }^{22-24}$ fluorometry, ${ }^{25-28}$ photometric titration $\operatorname{method}^{29-31}$ and a voltammetric method. ${ }^{32-34}$ However, only a few determination methods of PHMB-HCl have been reported. Hattori et al. ${ }^{34}$ have reported an indirect determination of PHMB by using adsorptive voltammetry of 2-(5-bromo-2-pyridyl)azo-5-[N-npropyl- $N$-(3-sulfopropyl)amino]phenol on a carbon paste electrode. They also have examined several titrimetric determinations for PHMB-HCl: Kjeldahl method, non-aqueous titration, argentometric titration and colloidal titration. ${ }^{35}$ Rowhani et $a l .{ }^{36}$ have developed a colorimetric assay determination using a complexation between $\mathrm{Ni}^{2+}$ and PHMB in pool and spa water. Abad-Villar et al. ${ }^{37}$ have demonstrated its capillary electrophoresis with contactless conductivity detection for the determination of $\mathrm{PHMB}-\mathrm{HCl}$ in eye drops. However, each measurement range of $\mathrm{PHMB}-\mathrm{HCl}$ concentration was above a few parts per million ( $\mathrm{ppm})$. Improvement of the sensitivity of the methods is required for determining a low concentration $(\sim 1$ $\mathrm{ppm}$ ) in such contact-lens detergents. Among the determination methods of cationic polyelectrolytes, ISE method is expected to

$\dagger$ To whom correspondence should be addressed.

E-mail: masadome@sic.shibaura-it.ac.jp be an alternative to these methods for the determination of $\mathrm{PHMB}-\mathrm{HCl}$ because the procedure of the ISE method can be easily performed and applied to colored samples and samples containing suspended solids..$^{3-21}$ Masadome et al. ${ }^{17,18}$ reported a potentiometric titration method of anionic polyelectrolytes such as poly(vinyl sulfate) (PVSK) by using a surfactant-selective electrode as an indicator electrode and a cationic polyelectrolyte, Cat-floc, solution as a titrant, where dodecylbenzene sulfonate (DBS) ion was added to a sample solution as an indicator ion. Just after the end-point of the titration, the concentration of free indicator ion decreases abruptly due to the ion association reaction between the indicator ion and the titrant. This decrease in the concentration of the indicator anion $\left(\mathrm{DBS}^{-}\right)$is detected as the potential jump of the surfactant-ISE and the end-point of the titration is determined.

Hattori et al. ${ }^{21}$ reported a potentiometric titration method for the determination of cationic polyelectrolytes using a surfactantISE developed by Masadome et al..$^{38-42}$ and TB cation as an indicator. The surfactant-ISE also responded to the TB cation. An end-point of the titration was detected as a sharp potential change due to an abrupt decrease in the indicator (TB) concentration caused by an ion association reaction between the TB ion and the titrant, PVSK. They applied the method to the determination of chitosan.

In our previous paper, ${ }^{19,20}$ we examined the potentiometric titration method of cationic polyelectrolytes using the same principle as that used in our potentiometric titration method of anionic polyelectrolytes. ${ }^{17,18}$ We found that the magnitude of potential change at the end-point depended on the hydrophobicity of the indicator ion; stearyltrimethylammonium and its ISE were found to be the best indicator cation and the best indicator electrode, respectively.

In the present paper, we will report a potentiometric titration 
<smiles>CC(C)(C)CCNC(=N)NC(=N)NCCCC(C)(C)Cl</smiles>

Fig. 1 Structure of PHMB-HCl.

method for the determination of PHMB-HCl using a cationic surfactant as an indicator cation and a plasticized poly(vinyl chloride) membrane electrode, which is sensitive to the cationic surfactant on the basis of the same principle as that used in our potentiometric titration method of cationic polyelectrolytes. ${ }^{19,20}$ Furthermore, the proposed method was applied to the determination of $\mathrm{PHMB}-\mathrm{HCl}$ in the contact-lens detergents.

\section{Experimental}

\section{Chemicals}

Sodium salt of tetrakis[3,5-bis(trifluoromethyl)phenyl]borate (NaTFPB) was used as the cation exchanger for cationic surfactant-selective electrodes. ${ }^{43,44}$ The NaTFPB was obtained from Dojindo Laboratories. According to the manufacturer's specification, the purity of the TFPB is more than $99.0 \%$. 2-Nitrophenyl octyl ether (NPOE) was also obtained from Dojindo Laboratories. The purity of the NPOE is more than $99.0 \%$, according to the manufacturer's specification. Hexadecyltrimethylammonium bromide (HTA), dodecyltrimethylammonium bromide (DTA) and tetradecyltrimethylammonium bromide (TTA) were obtained from Tokyo Chemical Industry Co., Ltd. PHMB-HCl was a $20 \%$ solution obtained from Avecia. The structure of the PHMB-HCl is shown in Fig. 1. A potassium poly(vinyl sulfate) (PVSK) solution for colloidal titration use was purchased from Wako Pure Chemicals Co. and was used as a titrant. The PVSK solution was standardized by the standard Zephiramine (tetradecyldimethylbenzylammonium chloride) solution using TB indicator. ${ }^{23,24}$ The concentration of a polyelectrolyte solution is expressed on the basis of a monomeric unit in $\mathrm{M}\left(\mathrm{mol} \mathrm{dm}{ }^{-3}\right)$, which indicates the moles of ionic group per liter of the polymer solution. Poly(vinyl chloride) (PVC) (degree of polymerization: 1100) was obtained from Wako Pure Chemicals Co. and was used without further purification. Other chemicals of guaranteed grade were used as received.

\section{Fabrication and assembly of the cationic surfactant-ISE}

The sensing membrane of the surfactant-ISE (HTA-ISE) was prepared from NPOE (1.0 g), NaTFPB (0.009 g) and PVC $(0.4 \mathrm{~g})$. A solution of $10^{-2} \mathrm{M}$ indicator ion and an $\mathrm{Ag} / \mathrm{AgBr}$ electrode were used as an inner solution and an inner reference electrode, respectively, for fabricating indicator-selective electrodes. The details of fabrication and assembly of the PVC membrane electrode were described in previous papers. ${ }^{38-44}$ The plasticized PVC membrane electrodes were conditioned with $1.0 \times 10^{-2} \mathrm{M}$ HTA solution for a minimum of 2 days.

\section{Standard procedure of potentiometric titration}

A PHMB-HCl sample solution containing $1.0 \times 10^{-5}$ or $5.0 \times$ $10^{-6} \mathrm{M}$ HTA and $1 \times 10^{-2} \mathrm{M} \mathrm{HCl}$ was prepared. A pair of the HTA-ISE and a double junction type reference electrode (DKK Type 4083) was immersed into the sample solution. The reference electrode used is a double junction-type $\mathrm{Ag} / \mathrm{AgCl}$ reference electrode with $3 \mathrm{M}$ potassium chloride as the inner

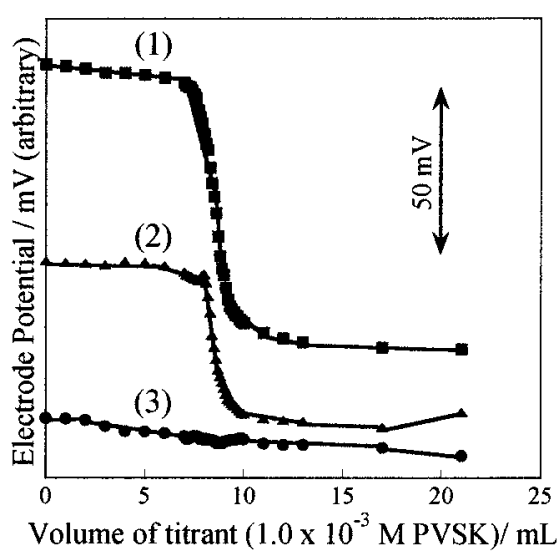

Fig. 2 Potentiometric titration curves of a PHMB-HCl solution with a PVSK solution by using indicator ion-selective electrodes. Titrant: $1.0 \times 10^{-3} \mathrm{M}$ PVSK solution. Sample: $40.00 \mathrm{~mL}$ of $1.0 \times 10^{-4} \mathrm{M}$ $\mathrm{PHMB}-\mathrm{HCl}$ solution containing $1.0 \times 10^{-2} \mathrm{M} \mathrm{HCl}$ and $1.0 \times 10^{-5} \mathrm{M}$ indicator ion. Indicator ion: (1) HTA, (2) TTA, (3) DTA. Indicator electrode: cationic surfactant-selective plasticized PVC membrane electrode based on TFPB.

filling solution and $1 \mathrm{M}$ lithium acetate as the outer filling solution. The resulting $\mathrm{PHMB}-\mathrm{HCl}$ solution (total volume: 40.00 or $50.00 \mathrm{~mL}$ ) was titrated with the $1.0 \times 10^{-3}$ or $1.0 \times 10^{-4}$ M PVSK standard solution. The emf of the couple of the electrodes was measured with an ion-meter (DKK IOL-40). The stable potential was read after an addition of suitable volume of the PVSK solution. PHMB-HCl in a real sample solution was determined by the calibration curve between the end-point volumes and the concentration of the PHMB-HCl.

\section{Results and Discussion}

\section{Selection of the indicator ion}

Figure 2 shows the potentiometric titration curves of the PHMB-HCl solution with the $1.0 \times 10^{-3} \mathrm{M}$ PVSK standard solution obtained by using several indicator ions (cationic surfactants) and the indicator (cationic surfactant)-selective electrodes. Since the potential of the indicator-ISE depends on the concentration of free indicator ion and since before the endpoint, the titrant, PVSK, preferentially forms the complex with the cationic polyelectrolyte sample, $\mathrm{PHMB}-\mathrm{HCl}$, the electrode potential gradually decreases as the titration proceeds. After the end-point, the electrode potential decreases abruptly corresponding to the decrease in the concentration of free indicator ion, since the titrant forms the complex with the indicator ion. When DTA ion was used as the indicator ion, the potential change of DTA-ISE at the end-point was negligibly small. This small potential change indicates that the concentration change of DTA ions at the end-point is small, which may be due to the fact that the possibility of ion association between PVSK and DTA ion is very small because the sensitivity of the indicator ISE was nearly the same for each indicator ion. On the other hand, when HTA and TTA ions were used as the indicator ion, a large potential change of each indicator ISE was observed at the end-point. For example, when the HTA ion was used as the indicator ion, a potential jump of about $80 \mathrm{mV}$ was observed at the end-point for the HTA-ISE, which was detected clearly as the end-point of the 


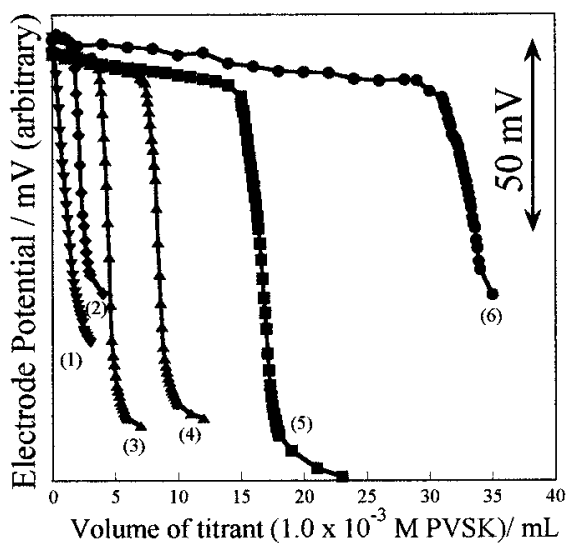

Fig. 3 Potentiometric titration curves for the PHMB- $\mathrm{HCl}$ solutions $\left(40.00 \mathrm{~mL}\right.$ ) containing $1.0 \times 10^{-2} \mathrm{M} \mathrm{HCl}$ with $1.0 \times 10^{-3} \mathrm{M}$ PVSK standard solution. Concentration of PHMB-HCl: (1) 0 , (2) $2.0 \times 10^{-5}$, (3) $4.0 \times 10^{-5}$, (4) $1.0 \times 10^{-4}$, (5) $2.0 \times 10^{-4}$, (6) $4.0 \times 10^{-4} \mathrm{M}$. Titrant: $1.0 \times 10^{-3} \mathrm{M}$ PVSK solution. Indicator ion: $1.0 \times 10^{-5} \mathrm{M}$ HTA.

titration. The point where the potential just began to drop was used as the end-point of the present titration. It is clear from Fig. 2 that the magnitude of the potential jump at the end-point increases in the order DTA $<$ TTA $<$ HTA. Since the magnitude of the potential jump is dependent on the magnitude of the decrease in the concentration of the indicator ion by ionpair formation with PVSK, the increasing order in the potential jump may be due to the fact that the association ability of the indicator ion with PVSK increases in the order: DTA $<<$ TTA $<$ HTA. These results show that the HTA ion is the best indicator ion among the indicator ions examined in this work. All experimental results described below were obtained using the HTA ion as the indicator ion and the HTA-ISE. According to the colloidal titration of PHMB-HCl by TB indicator at less than $\mathrm{pH} 2,{ }^{34}$ the result agreed with the total value of non-aqueous titration and argentometric titration. Thus, one mole of the unit concentration of $\mathrm{PHMB}-\mathrm{HCl}$ quantitatively reacted with two moles of the unit concentration of PVSK. The end-point volume, obtained by the potentiometric titration curves using the HTA ion as the indicator ion and the HTA-ISE, agreed with the volume calculated from the 1:2 reaction within an error of less than about $8 \%$.

\section{Effect of concentration of the indicator cation}

When the concentration of the HTA ion and the PVSK (a titrant) are $1.0 \times 10^{-5}$ and $1.0 \times 10^{-3} \mathrm{M}$, respectively, $\mathrm{PHMB}-\mathrm{HCl}$ in $10^{-5} \mathrm{M}$ order was determined. Generally, the concentration of PHMB-HCl in commercial contact-lens detergents is $c a .1 .1$ ppm $\left(5.0 \times 10^{-6} \mathrm{M}\right)$. To determine PHMB-HCl in the contactlens detergents, we optimized the concentration of the HTA. The effect of the concentration of the indicator cation (HTA) on the potential change at the end-point for titration of $50.00 \mathrm{~mL}$ of the $5.0 \times 10^{-6} \mathrm{M}$ PHMB-HCl solution with the $1.0 \times 10^{-4} \mathrm{M}$ PVSK standard solution was examined. In the concentration range of the HTA from $1.0 \times 10^{-6}$ to $5.0 \times 10^{-6} \mathrm{M}$, a small potential change at the end-point was observed. When the concentration of HTA is $1.0 \times 10^{-5} \mathrm{M}$, the sharpness of the endpoint detection is inferior to that in the concentration range of the HTA from $1.0 \times 10^{-6}$ to $5.0 \times 10^{-6} \mathrm{M}$. When the indicator ion is not contained in the PHMB-HCl sample solution, a potential change near the expected end-point was not observed. This may be due to the fact that the surfactant-ISE responds to

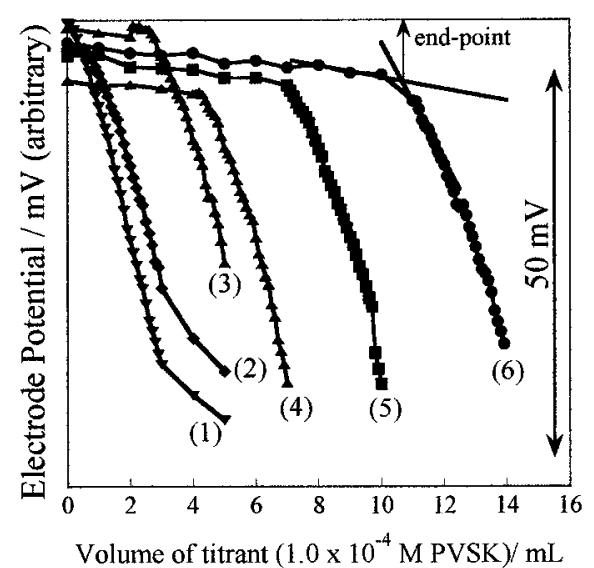

Fig. 4 Potentiometric titration curves for the $\mathrm{PHMB}-\mathrm{HCl}$ solutions $(50.00 \mathrm{~mL})$ containing $1.0 \times 10^{-2} \mathrm{M} \mathrm{HCl}$ with $1.0 \times 10^{-4} \mathrm{M}$ PVSK standard solution. Concentration of PHMB-HCl: (1) 0 , (2) $1.0 \times 10^{-6}$, (3) $3.0 \times 10^{-6}$, (4) $5.0 \times 10^{-6}$, (5) $8.0 \times 10^{-6}$, (6) $1.2 \times 10^{-5} \mathrm{M}$. Titrant: $1.0 \times 10^{-4} \mathrm{M}$ PVSK solution. Indicator ion: $5.0 \times 10^{-6} \mathrm{M}$ HTA.

neither PHMB-HCl nor PVSK. From the results, the concentration of the indicator cation (HTA) was decided to be $5.0 \times 10^{-6} \mathrm{M}$ in order to determine PHMB- $\mathrm{HCl}$ at $10^{-6} \mathrm{M}$ order by considering the fact that the detection limit of the surfactantISE is approximately $1.0 \times 10^{-6} \mathrm{M}$.

\section{Effect of inorganic electrolytes}

In a conventional colloidal titration method using the TB indicator, coexisting inorganic electrolytes lead to titration errors $^{23,24}$ because common cations or anions tend to form ion associates with polyanions or polycations in the sample solution or titrant. Here, the effect of electrolytes on the relative error of the present titration of $1.0 \times 10^{-4} \mathrm{M}$ PHMB- $\mathrm{HCl}(40.00 \mathrm{~mL})$ with $1.0 \times 10^{-3} \mathrm{M}$ PVSK standard solution, when the PHMB$\mathrm{HCl}$ sample solution contains $1.0 \times 10^{-2} \mathrm{M} \mathrm{NaCl}$ or $1.0 \times 10^{-2} \mathrm{M}$ $\mathrm{CaCl}_{2}$, respectively, was examined. The magnitude of potential change at the end-point decreases slightly in the presence of coexisting $\mathrm{NaCl}$. This may be due to the fact that $\mathrm{Na}^{+}$ions lower the ability of ion associations between PVSK and the indicator ions, HTA ions. However, the end-point was detected even in the presence of 100 -fold excess $\mathrm{NaCl}$ to the concentration of PHMB-HCl. Furthermore, the relative titration error [(end-point volume at $1.0 \times 10^{-2} \mathrm{M} \mathrm{NaCl}-$ end-point volume at $0 \mathrm{M} \mathrm{NaCl}) /($ end-point volume at $0 \mathrm{M} \mathrm{NaCl}$ )] was $c a$. $-2.0 \%$ in the presence of $1.0 \times 10^{-2} \mathrm{M} \mathrm{NaCl}$. On the other hand, the magnitude of potential change at the end-point decreases remarkably in the presence of $\mathrm{CaCl}_{2}$, compared with $\mathrm{NaCl}$. This may be due to the fact that $\mathrm{Ca}^{2+}$ ion can lower the ability of an ion association between PVSK and indicator ion, HTA ion, because a divalent ion, $\mathrm{Ca}^{2+}$ ion, forms an ion complex more strongly with PVSK than $\mathrm{Na}^{+}$ion can. The relative titration error was ca. $-5.0 \%$ in the presence of $1.0 \times 10^{-2} \mathrm{M} \mathrm{CaCl}_{2}$.

\section{Measurable concentration range of the present titration method}

Most of the biguanide groups in a PHMB-HCl dissociate completely at about $\mathrm{pH} 2.0 .^{35}$ Here, in order to evaluate the measurable concentration range of the present method, we constructed calibration curves at $\mathrm{pH} 2.0$ adjusted with $0.1 \mathrm{M}$ $\mathrm{HCl}$, according to standard procedures. Figures 3 and 4 show the titration curves for $\mathrm{PHMB}-\mathrm{HCl}$ solutions at different concentrations with $1.0 \times 10^{-3}$ and $1.0 \times 10^{-4} \mathrm{M}$ PVSK standard solution, respectively. When the potential gradually decreased 
after the end-point of the titration with $1.0 \times 10^{-4} \mathrm{M}$ PVSK standard solution, the end-point was detected by extrapolation with the two lines as shown in Fig. 4.

For the PHMB-HCl solutions examined, the end-points were detected even in the $10^{-6}$ and $10^{-5} \mathrm{M}$ range, sensitively. The calibration curves between the end-point volume and the concentration of the PHMB-HCl were linear over the range from $2.0 \times 10^{-5}$ to $4.0 \times 10^{-4} \mathrm{M}$ and from $1.0 \times 10^{-6}$ to $1.2 \times 10^{-5}$ $\mathrm{M}$, respectively. The calibration curve equations are $Y=0.7779$ $\times 10^{5} X-0.0198(\gamma=0.9995)$ for PHMB-HCl solutions in the concentration range from $2.0 \times 10^{-5}$ to $4.0 \times 10^{-5} \mathrm{M}$ and $Y=0.9195 \times 10^{6} X-0.0940(\gamma=0.9993)$ for PHMB-HCl solutions in the concentration range from $1.0 \times 10^{-6}$ to $1.2 \times 10^{-5}$ $\mathrm{M}$, respectively. Here, $Y$ is the end-point volume and $X$ the molar concentration of the PHMB-HCl solution. The relative standard deviations of the end-point volume for three times of PHMB-HCl titrations were $5.2 \%$ for $3.0 \times 10^{-6} \mathrm{M}$ PHMB-HCl, and less than $0.50 \%$ for $8.0 \times 10^{-6} \mathrm{M}$ PHMB-HCl, respectively.

Application of the proposed method to the determination of $\mathrm{PHMB}-\mathrm{HCl}$ in the contact-lens detergents

A commercial contact-lens detergent $(200.0 \mathrm{~mL})$ was mixed with $\mathrm{HTA}$ and $\mathrm{HCl}$ solutions and the mixed solutions were made up to $250.0 \mathrm{~mL}$ with distilled and deionized water. The resulting solution contains $5.0 \times 10^{-6} \mathrm{M}$ HTA and $\mathrm{pH}$ of the solution is $c a$. 2.0. From a linear relationship between the concentration of added PHMB-HCl to the resulting solution and the end-point volume of the titrant for the resulting solution containing PHMB-HCl, PHMB-HCl in a commercial contactlens detergent was determined based on a standard addition method. The concentration of $\mathrm{PHMB}-\mathrm{HCl}$ in a commercial contact-lens detergent is $1.05 \mathrm{ppm}\left(4.8 \times 10^{-6} \mathrm{M}\right)$ and coincides with the nominal value $\left(1.1 \mathrm{ppm}, 5.0 \times 10^{-6} \mathrm{M}\right)$.

This result shows that the present potentiometric titration can be applied to determine the level of $\mathrm{PHMB}-\mathrm{HCl}$ in a commercial contact-lens detergent.

\section{Conclusions}

The end-point in the potentiometric titration of $\mathrm{PHMB}-\mathrm{HCl}$ was sensitively detected by use of the HTA-ISE as an indicator electrode and the HTA indicator ion. The advantages of our potentiometric titration method for the determination of PHMB$\mathrm{HCl}$ are better sensitivity than those in the reported methods ${ }^{35-37}$ and its applicability to colored and suspended solutions and related types of samples. By the proposed potentiometric titration method, $\mathrm{PHMB}-\mathrm{HCl}$ in a contact-lens detergent can be determined.

\section{References}

1. K. Toei and T. Kohara, Anal. Chim. Acta, 1976, 83, 59.

2. K. Toei and M. Sawada, Anal. Chim. Acta, 1977, 89, 383.

3. S.-C. Ma, V. C. Yang, and M. E. Meyerhoff, Anal. Chem., 1992, 64, 694.

4. S.-C. Ma, V. C. Yang, B. Fu, and M. E. Meyerhoff, Anal. Chem., 1993, 65, 2078.

5. B. Fu, E. Bakker, J. H. Yun, E. Wang, V. C. Yang, and M. E. Meyerhoff, Anal. Chem., 1994, 66, 2250.

6. B. Fu, E. Bakker, J. H. Yun, E. Wang, V. C. Yang, and M. E. Meyerhoff, Electroanalysis, 1995, 7, 823.

7. J. M. Esson and M. E. Meyerhoff, Electroanalysis, 1997, 9, 1325.
8. S. Dai, J. M. Esson, O. Lutze, N. Ramamurthy, V. C. Yang, and M. E. Meyerhoff, J. Pharm. Biomed. Anal., 1999, 19, 1.

9. N. Ramamurthy, N. Baliga, T. W. Wakefield, P. C. Andrews, V. C. Yang, and M. E. Meyerhoff, Anal. Biochem., 1999, 266, 116.

10. J. M. Esson, N. Ramamurthy, and M. E. Meyerhoff, Anal. Chim. Acta, 2000, 404, 83.

11. Q. Ye and M. E. Meyerhoff, Anal. Chem., 2001, 73, 332.

12. N. Dueruest and M. E. Meyerhoff, J. Electroanal. Chem., 2007, 602, 138.

13. J. Langmaier, E. Samcová, and Z. Samec, Anal. Chem., 2007, 79, 2892.

14. T. Hattori, T. Kawanishi, and M. Kato, Bull. Chem. Soc. Jpn., 1994, 67, 405.

15. J.-M. Sequqris and P. Kalabokas, Anal. Chim. Acta, 1993, $281,341$.

16. N. Ishibashi, K. Kina, and K. Tamura, Anal. Lett., 1975, 8, 867.

17. T. Masadome and T. Imato, Fresenius J. Anal. Chem., 1995, 352, 596.

18. T. Masadome, T. Imato, and Y. Asano, Fresenius J. Anal. Chem., 1999, 363, 241.

19. T. Masadome and T. Imato, Anal. Commun., 1997, 34, 257.

20. T. Masadome and T. Imato, Talanta, 2003, 60, 663.

21. T. Hattori, K. Katai, M. Kato, M. Izume, and Y. Mizuta, Bull. Chem. Soc. Jpn., 1999, 72, 37.

22. D. Horn, Prog. Colloid Polym. Sci., 1978, 65, 251.

23. R. Senju, "Koroido Tekiteihou (Colloidal Titration, in Japanese)", 1960, Nankodo, Tokyo.

24. K. Ueno and K. Kina, J. Chem. Educ., 1985, 62, 627.

25. K. Kina, K. Tamura, and N. Ishibashi, Bunseki Kagaku, 1974, 23, 1082.

26. K. Kina, K. Tamura, and N. Ishibashi, Bunseki Kiki, 1976, $14,551$.

27. H. Tanaka and Y. Sakamoto, J. Polym. Sci., 1993, 31, 2687.

28. H. Tanaka and Y. Sakamoto, J. Polym. Sci., 1993, 31, 2693.

29. T. Masadome and Y. Hoshi, Microchim. Acta, 2003, 142, 37.

30. T. Masadome, M. Kawaguchi, and L. Kurniasari, Anal. Lett., 2003, 36, 619.

31. T. Masadome, Talanta, 2003, 59, 659.

32. V. P. Y. Gadzekpo, K. P. Xiao, H. Aoki, P. Bühlmann, and Y. Umezawa, Anal. Chem., 1999, 71, 5109.

33. V. P. Y. Gadzekpo, P. Bühlmann, K. P. Xiao, H. Aoki, and Y. Umezawa, Anal. Chim. Acta, 2000, 411, 163.

34. T. Hattori, N. Tsurumi, R. Kato, and M. Nakayama, Anal. Sci., 2006, 22, 1577.

35. T. Hattori, Y. Nakata, and R. Kato, Anal. Sci., 2003, 19, 1525.

36. T. Rowhani and A. F. Lagalante, Talanta, 2007, 71, 964.

37. E. M. Abad-Villar, S. F. Etter, M. A. Thiel, and P. C. Hauser, Anal. Chim. Acta, 2006, 561, 133.

38. N. Ishibashi, T. Masadome, and T. Imato, Anal. Sci., 1986, 2, 487.

39. T. Masadome, T. Imato, and N. Ishibashi, Anal. Sci., 1987, 3,121 .

40. T. Masadome, J.-G. Yang, T. Imato, and N. Ishibashi, Bunseki Kagaku, 1992, 41, 231.

41. T. Masadome, T. Imato, and N. Ishibashi, Anal. Sci., 1990, 6, 605 .

42. T. Masadome, T. Imato, and N. Ishibashi, Bunseki Kagaku, 1990, 39, 519 .

43. T. Masadome, Microchim. Acta, 2002, 140, 227.

44. T. Masadome, K. Yada, and S. Wakida, Anal. Sci., 2006, 22,1065 . 